\title{
Age Determination of Ayu with Otolith
}

\author{
Katsumi Tsukamoto*1 and Takeshi Kajihara*2
}

(Accepted March 28, 1987)

\begin{abstract}
The growth increments in otolith were validated to establish the age determination method of the ayu Plecoglossus altivelis an amphidromous salmonoidei fish with 1 year life span.

Newly hatched larvae have ca. 5 embryonic increments in a circular sagitta of ca. $15 \mu \mathrm{m}$ radius. No mark peculiar to the time of hatch was detected in sagitta. Sequential samplings of known age fish from a rearing pond and those released in a river demonstrated that the days after hatching and the number of sagittal increments outside the $15 \mu \mathrm{m}$ radius presented close linear regressions with the slopes of 1.007 (1-150 days), 0.950 (120-180 days) and 0.871 (215-355 days), suggesting a daily deposition of the increment in sagittae. This was supported by the tetracycline marking of otolith in both larvae and juveniles.

Ages of fish over 200 days old tended to be slightly underestimated, because the earlier increments arround the focus became invisible due to thickening and brownish coloration of otolith accompanied by fish growth, and further because the occurrence of conspicuous opaque bands (checks) corresponding to the tentative cessation of increment formation increased in older fish. The error, however, did not exceed 5 days $(2 \%)$ till 300 days old, and the age determination method was applicable to the ecological study of this species for almost the entire life cycle.
\end{abstract}

Pannella's ${ }^{1)}$ discovery of daily growth increments in otoliths proved to be an incentive that caused a bloom of otolith research. It has a potential to increase the resolution and precision of age determination and promises to provide fisheries biologists with new levels of information. $^{2)}$ Validation of the deposition rate of increments is a necessary prerequisite to otolith microstructure work of any kind. Only a few studies, however, have provided a full-scale validation of the increment frequency and indeed, as Campana and Neilson ${ }^{3)}$ mentioned, the results of many studies carried the explicit assumption that the otolith increments were formed daily.

The ayu Plecoglossus altivelis is an amphidromous salmonoidei fish with 1 year life span and one of the important species in Japan in game fishing as well as in fish culture. Larvae hatched in autumn at lower reaches of a river ( 6 $\mathrm{mm}$ in body length) are drifted downward and spend winter months in the sea. Juveniles (ca. $60 \mathrm{~mm}$ ) start the upstream migration in spring and spend their latter half of life in the fresh water. Their life in the sea is still unclear, although a great deal of information has been accumulated on the freshwater stage., ${ }^{45}$ The establishment of age determination technique in daily precision for the earlier half of their life will bring a big progress on its ecology and population dynamics, since this is suspected from the analogy to other species as the period of mass mortality holding the key in the population fluctuation.

The objective of the present study is to validate the deposition rate of growth increment in the otolith of ayu, and to establish the age determination method for the study of life history and population dynamics of this species.

\section{Materials and Methods}

\section{Experimental Design}

This study was devided into the following three parts: (1) morphology of otolith, (2) validation of increment and (3) age determination. First, the morphological characteristics and the development of three pairs of otolith, sagitta, lapillus and asteriscus, were examined and the most suitable one for age determination was selected using the sequential sacrifice from three lots of artificially fertilized fish (Fish A, B, C, Table 1). Next, the increment in otolith was validated through tetracycline marking in larvae and juvenile (Fish $G$ and

*1 Ocean Research Institute, University of Tokyo, Nakano, Tokyo 164, Japan (塚本勝 巳：東京大学海洋研究 所).

*2 Environmental Biology Research Center Co. Ltd., 1-3-8 Nakameguro, Meguro, Tokyo 153, Japan (梶原 武: 環境生物研究所). 
Table 1. Materials used in the study

\begin{tabular}{|c|c|c|c|c|c|c|c|}
\hline $\begin{array}{l}\text { Fish } \\
\text { group }\end{array}$ & $\begin{array}{l}\text { No. } \\
\text { fish }\end{array}$ & $\underset{(\mathrm{mm})}{\mathrm{SL}}$ & Birthdate & $\begin{array}{c}\text { Age } \\
\text { (day) }\end{array}$ & $\begin{array}{c}\text { Developmental } \\
\text { stage }\end{array}$ & $\begin{array}{l}\text { WT } \\
\left({ }^{\circ} \mathrm{C}\right)\end{array}$ & Environment remarks \\
\hline \multicolumn{8}{|c|}{ Age Determination \& Morphology (Rearing and sequential sacrifice) } \\
\hline Fish A & 92 & $5.7-50.3$ & Oct. $26^{\prime} 82$ & $1-150$ & larva-juvenile & $11-18$ & Reared in Oita hatchery \\
\hline Fish B & 16 & $43.0-69.8$ & Oct. $10 ' 82$ & $120-180$ & juvenile & $12-20$ & Reared in Hiroshima hatchery \\
\hline Fish C & 26 & $62.7-172.3$ & Oct. 10 '81 & $215-355$ & juvenile-adult & $15-28$ & $\begin{array}{l}\text { Released in the River Tsubusa } \\
\text { (fin-clipped) }\end{array}$ \\
\hline \multicolumn{8}{|c|}{ Otolith at hatching (Egg incubation) } \\
\hline Fish D & 30 & 4.6 & Oct. 8 ' 84 & 0 & & $17-25$ & Incubated in the \\
\hline Fish $\mathbf{E}$ & 59 & 6.7 & Oct. 19 ' 84 & 0 & va & $16-17$ & Incubated at Nïigata Labo. \\
\hline Fish $\mathbf{F}$ & 57 & 6.7 & Oct. $20^{\prime} 84$ & $\mathbf{0}$ & larva & 13-14 & $\begin{array}{l}\text { Incubated in waters of } \\
\text { the River Shinano }\end{array}$ \\
\hline \multicolumn{8}{|c|}{ Validation of Increment (Tetracycline marking) } \\
\hline Fish $\mathrm{G}$ & 93 & $5.0-9.5$ & Oct. $21-25^{\prime} 84$ & $1-8$ & & $16-22$ & Release \\
\hline Fish $\mathrm{H}$ & 50 & 65.0 & Oct. $10 ’ 81$ & 230 & juvenile & $18-21$ & Kept at Oita Labo. \\
\hline
\end{tabular}

$\mathrm{H}$, respectively). Lastly, age determination method was established by estimating the ageing error on the sequential samples of known age (Figs A, B, $C)$, after determining the radius and the number of embryonic increment in otolith of newly hatched larvae incubated under different conditions (Fish D, E, F).

\section{Fish}

Eight groups of fish which had different growth histories and/or experimental treatments were used in the study (Fish A-H, Table 1). All but Fish $D$, wild larvae, were artificially fertilized.

Fish A, B and C were sequential samples and were reared in the sea water of indoor tank and fed 2-3 times daily with rotifer, artemia and artificial diet (Nihon Nousan, Diet for Larval Ayu \#1-4). About 30 fish were sampled at 4 30 days interval. Fish A covered 150 days period after hatching and Fish B, 60 days (120-180 days after hatching).

Fish $\mathrm{C}$ were incubated at Hiroshima Hatchery as Fish $\mathrm{B}$ but in different year, and reared there till ca. $\mathbf{2 0 0}$ days old. Afterwards, they were used in the mark-recapure study in the River Tsubusa, Oita Prefecture. About 10,000 juveniles (215 days old, $62.7 \mathrm{~mm}$ in mean standard length) were released after adipose fin clipping on May 18, 1982 and ca. 1500 individuals were recaptured by the end of September using gill net, fish pot, set net with trap and decoy fishing (tomo-zuri). Fish $C$ were sampled from the recapture at interval of 16-38 days for 140 days after the release and about 5 fish were selected at each sampling time (6 samplings and 26 individuals in total) for otolith examination. The last sample recaptured on September 30 (355 days old) grew to $172.3 \mathrm{~mm}$ (mean) in standard length and the gonads were partly matured (Gonad Somatic Index; ca. 5-15).

Fish D-F were newly-hatched larvae incubated from eggs under different conditions. These fish were used in order to determine the otolith size at hatching and the number of embryonic increment. Fish D were larvae hatched out of naturally fertilized eggs of land-locked ayu in the Lake Biwa. Eggs were collected carefully together with adhered gravels at the spawning ground of the River Inukami, an inlet stream of the lake, and were incubated in situ in a cage. Fish $\mathrm{E}$ and $\mathrm{F}$ were larvae newly-hatched out of artificially fertilized eggs of an amphidromous stock. Fish $\mathrm{E}$ was kept in fresh water at Niigata Pref. Freshwater Fisheries Experimental Station, and Fish F, in the water of the River Shinamo. These larvae (D-F) were killed immediately $(0-3 \mathrm{~h})$ after hatching.

Fish $\mathrm{G}$ and $\mathrm{H}$ were used in tetracycline marking experiments to validate the growth increment in larval and juvenile otoliths, respectively. Fish G were artificially fertilized using parents caught in the River Kiso and were incubated at $19^{\circ} \mathrm{C}$ till the transport. Before the release, the fertilized eggs were transported to Ugui Marine Biological Station, and a part of them (ca. 4,000,000 eggs) were marked in the otolith in tetracycline hydrochloride solution $(300 \mathrm{mg} / l)$ for $\left.48 \mathrm{~h} .{ }^{6}\right)$ The remaining eggs were incubated in $1000 \mathrm{l}$ plastic tank at ca. $20^{\circ} \mathrm{C}$ till hatching and newly hatched larvae (ca. $3,000,000$ ) were immersed in $200 \mathrm{mg} / \mathrm{l}$ tetracycline solution for $24 \mathrm{~h}^{\mathrm{B})}$ Marked eggs attached to the matrix were immersed at the lower reaches of the River Nagano (Wakayama Pref.) and the waterflow carried the resulting larvae downward to the mouth of the river and to the Ugui Cove. Larvae 
marked after hatching were released directly at the mouth of the river. About 500 larvae with fluorescent mark on the otolith were recaptured in the Ugui Cove within 6 days after the release.*3 of these a total of 93 individuals were examined for the otolith (2-77 fish for each of 5 samplings with 1-2 days interval). Fish $\mathrm{H}$ is represented by 50 juveniles having same growth history with those of Fish C. When they were about 230 days old, their otoliths were marked twice with 8 days interval by intraperitoneal injections $(0.05-0.10 \mathrm{~m} /$ animal) of tetracycline hydrochloride solution $(3 \mathrm{mg} / \mathrm{ml})$. As a control, additional 50 fish were treated similarly with two injections of $0.75 \% \mathrm{NaCl}$ solution. These fish were kept at ca. $18^{\circ} \mathrm{C}$ in the indoor tank without food. The survived fish were killed 8 days after the second injection.

All samples, Fish A-H, were preserved in 70$90 \%$ ethanol before extraction of otolith.

\section{Otolith Preparation}

As a principle, only a pair of sagitta were removed under a binocular microscope (Nikon SMZ-10) at 10-40x magnification, after standard length was measured with a sliding micrometer projector (Nikon, Sokubikei) mounted to the binocular for larvae, or digital calipers (Japan Micrometer, NSK Max-cal) for juveniles and adults. As for Fish A, lapilli and asterisci as well as sagittae were extracted in order to compare the developments of three pairs of otolith. The otoliths were mounted on a glass microscope slide with a drop of mounting medium (Euparal, Chroma-Gesellschaft) and a coverslip. To protect otolith from being crushed during hardening of the medium, 2-3 pieces of fishing line (ca. $2 \mathrm{~cm}$ long, $0.1-0.5 \mathrm{~mm}$ in diameter) or straight human hair with appropriate diameter were mounted together.

\section{Otolith Measurement}

Sagitta was measured from the nucleus to the posterior edge using an ocular micrometer in a compound light microscope (Nikon, Optiphoto) at $60-600 \mathrm{x}$. It was used as radius, although it was mathematically incorrect in a strict sense. At the same time, the radius of the innermost distinguishable increment (RIDI) was also measured in the same way. In lapillus, the largest radius was measured. Asteriscus was roughly regarded as a rectangle and its length and width were measured.

\section{Counting}

Only one otolith of either side was arbitrarily selected for reading. As for Fish D-F and a part of Fish A (1, 10, 45 and 120 days old samples), however, both right and left sagittae of each individual were examined for bilateral comparison of deposition rate, readability or size. A bipartite structure of a narrow opaque band (discontinuous zone) and an adjacent wider translucent band (incremental zone) ${ }^{7\rangle}$ was regarded as one growth increment. In sagittae of Fish A-C, the increments within the $15 \mu \mathrm{m}$ radius were conventionally regarded as those deposited before hatching (embryonic increments) and those outside the $15 \mu \mathrm{m}$ radius were counted as representing postnatal growth, since the mean radius of sagittae at hatching was estimated as ca. $15 \mu \mathrm{m}$ in Fish D-F (see below). As for lapilli of Fish A, all increments were counted from the innermost distinguishable one to the edge. In sagittae of Fish D-F, all increments visible were also counted as embryonic ones.

With the help of two sets of arrow marker projector (Nikon, Teching Head) fitted into compound light microscope, counting was made from inside to outside in the following mannar. About $10-40$ increments sectioned by two arrows were counted at a time and the number was recorded. Then, only the inner arrow, the outer one being fixed, was moved outside of the other arrow onto the next reference point on the otolith, e.g. a check (conspicuous opaque band), a crack or a stain. The increments in the next section were counted similarly and this procedure was repeated to the edge of otolith. At the end of reading, all counts for each section were added to obtain the total number of increments after hatching. In sagitta, counting was usually made from the center to the posterior edge along the long axis of the otolith, or to the dorso-anterior edge, where subdaily increments seldom occurred even in old fish, although the increment width was smaller than that in the posterior part. No particular counting route was adopted in lapillus.

All the otolith preparations were blind-labeled and were counted in a random sequence by two independent readers. Each reader usually counted every otolith only once, since the repeatability of reading by our method was satisfactory.** Agreement of the two readers within $5 \%$ of the mean was considered acceptable and the mean was

*3 The details of this mark-recapture experiment will be published elsewhere (Tsukamoto et al.).

*4 Error $<3 \%$ in 120 days old fish, (Tsukamoto and Kajihara, unpublished). 
adopted for the analysis. When the difference exceeded $5 \%$, the preparation was discarded. ${ }^{* 5}$ In case of fish younger than 60 days old, the disagreement of less than 3 increments was accepted even when it exceeded $5 \%$. Otolith anomalies, multiple-growth focii and/or low transparency due to heavy coloration were found in about $3 \%$ of otoliths examined, and they were also excluded from the following analysis.

Tetracycline marked otoliths in Fish $\mathrm{G}$ and $\mathrm{H}$ were examined with a compound light microscope fitted with fluorescence attachment (Nikon EF, reflection type) and two sets of arrow marker projector. At first, otolith was observed under ultraviolet light and the position of tetracycline fluorescent band was pointed with an arrow image. Then it was observed under normal white light without any additional changes in the microscopic observation. The number of increments between two arrows (in Fish $\mathrm{H}$ ), or between the arrow and the edge of otolith (in Fish G) was counted.

\section{Results}

\section{Morphology of Otolith}

The ayu has three pairs of otoliths of different shapes and growth patterns, i.e. lapillus, sagitta and asteriscus (Fig. 1). Both sagitta and lapillus are already formed at hatching, while asteriscus is not observed until 20 days after hatching (Table 2). Sagitta, the largest of the three, is orbicular till 20 days after hatching and afterwards, the anterior margin protrudes to attain a shape of sagitta (Fig. 2). The lapillus is roughly orbicular till the age of 150 days. On the other hand, a core of asteriscus is formed through the coherence of several granules (3-8 $\mu \mathrm{m}$ in diameter) at the age of about 30 days, and at the age of 45-60 days, a protuberance grows from the core to form the shape of "comma", or "wedge" (Fig. 1).

Otoliths are clear and transparent in both reared and field-collected fish younger than ca. 100 days old (Fig. 3). Distinct concentric rings (increment) are observed in both sagitta (Fig. 3) and lapillus (Fig. 1), whereas similar incremental layers in asteriscus are more irregular and faint (Fig. 1).

The number of increments in lapillus is about 5 at hatching, and it shows a good linear correlation with the days after hatching on $20-150$ days old fish. The slope of regression line was ca. 1 (Fig. 4). However, the correlation is completely lost on 0-20 days old fish, suggesting the temporary cessation of increment formation. Furthermore, the width of each increment (mean, $1.2 \mu \mathrm{m}$ )

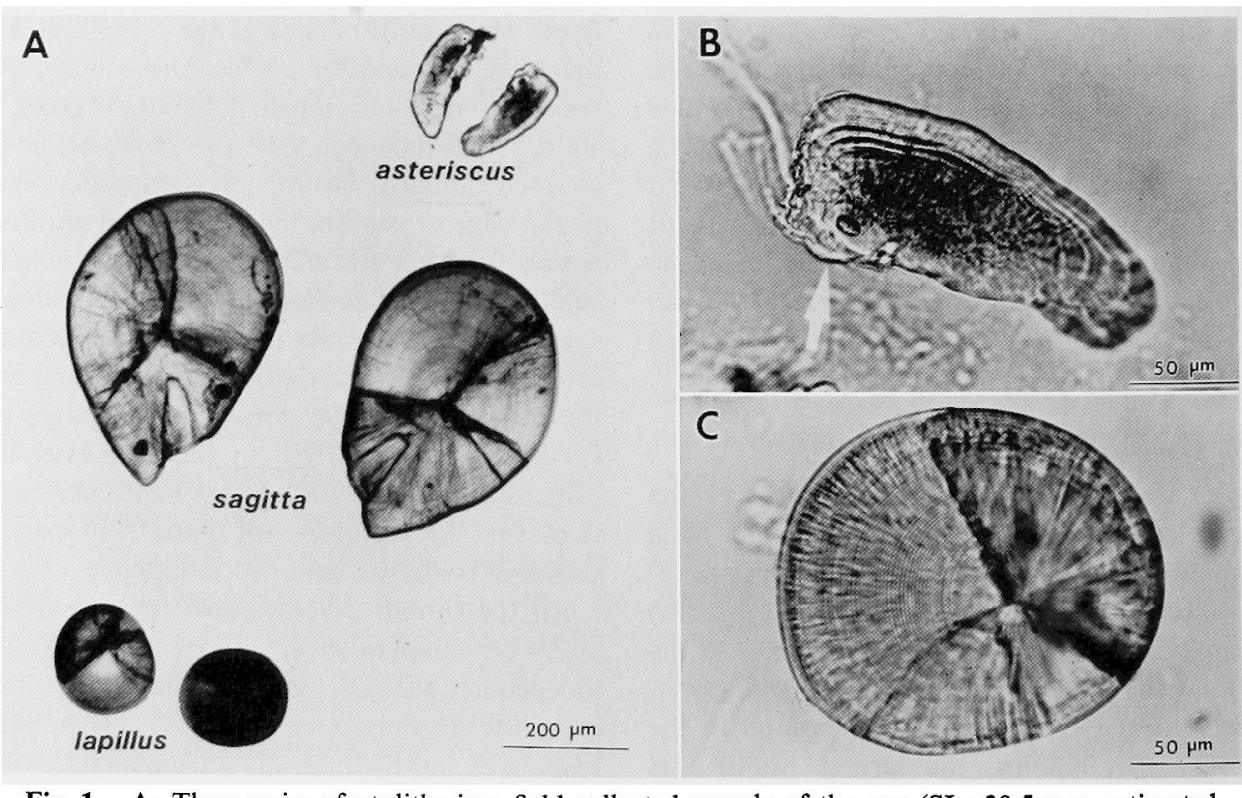

Fig. 1. A : Three pairs of otoliths in a field collected sample of the ayu (SL; $30.5 \mathrm{~mm}$, estimated age; 76 days old). B: Asteriscus. Arrow shows the core of multiple-growth foci. C: Lapillus. Growth increments are clear but narrow.

*5 These discarded otolith amounted $<2 \%$ of all otoliths examined, (Tsukamoto and Kajihara, unpublished). 
Table 2. Growth of three kinds of otoliths of the ayu

\begin{tabular}{|c|c|c|c|c|c|c|c|c|}
\hline \multirow[b]{2}{*}{$\begin{array}{l}\text { Age } \\
\text { (day) }\end{array}$} & \multirow[b]{2}{*}{$\begin{array}{l}\text { No. } \\
\text { fish }\end{array}$} & \multirow[b]{2}{*}{$\begin{array}{r}\mathrm{SL}(\mathrm{mm}) \\
\text { mean } \pm \mathrm{SD}\end{array}$} & \multicolumn{2}{|r|}{ Sagittae } & \multicolumn{2}{|r|}{ Lapilli } & \multicolumn{2}{|r|}{ Asterisci } \\
\hline & & & $\begin{array}{l}\text { No. } \\
\text { otolith }\end{array}$ & $\begin{array}{c}\text { Radius } \\
(\mu \mathrm{m})^{* 1} \\
\text { mean } \pm \mathrm{SD}\end{array}$ & $\begin{array}{l}\text { No. } \\
\text { otolith }\end{array}$ & $\begin{array}{c}\text { Radius } \\
(\mu \mathrm{m})^{* 2} \\
\text { mean } \pm \mathrm{SD}\end{array}$ & $\begin{array}{l}\text { No. } \\
\text { otolith }\end{array}$ & Size $(\mu \mathrm{m})^{* 3}$ \\
\hline \multicolumn{9}{|l|}{ Fish A } \\
\hline 1 & 13 & $5.7 \pm 0.2$ & 17 & $15.8 \pm 2.0$ & 8 & $10.4 \pm 0.7$ & - & - \\
\hline 5 & 13 & $6.8 \pm 0.4$ & 16 & $21.2 \pm 1.3$ & 10 & $13.0 \pm 0.4$ & - & - \\
\hline 10 & 6 & $8.1 \pm 0.8$ & 12 & $28.2 \pm 1.2$ & 9 & $14.5 \pm 0.4$ & - & - \\
\hline 20 & 6 & $11.1 \pm 1.7$ & 10 & $45.9 \pm 5.2$ & 10 & $18.9 \pm 1.1$ & 2 & $3.2-8.0 \times 3.2-8.0$ \\
\hline 30 & 6 & $16.2 \pm 1.5$ & 11 & $89.6 \pm 7.1$ & 13 & $27.6 \pm 4.6$ & 3 & $13.5-57.2 \times 11.1-27.0$ \\
\hline 45 & 7 & $24.2 \pm 1.5$ & 12 & $137.3 \pm 26.0$ & 26 & $50.7 \pm 5.0$ & 22 & $28.6-89.0 \times 19.1-50.9$ \\
\hline 60 & 6 & $29.5 \pm 1.2$ & 6 & $138.9 \pm 10.0$ & 16 & $65.8 \pm 9.1$ & 19 & $50.9-147.9 \times 31.8-111.3$ \\
\hline 90 & 6 & $35.5 \pm 1.5$ & 6 & $192.4 \pm 12.4$ & 15 & $94.1 \pm 15.7$ & 18 & $95.4-305.3 \times 55.7-104.9$ \\
\hline 120 & 20 & $43.5 \pm 3.2$ & 31 & $305.7 \pm 41.7$ & 19 & $133.7 \pm 16.0$ & 33 & $159.0-368.9 \times 82.7-171.7$ \\
\hline 150 & 9 & $50.3 \pm 4.1$ & 10 & $457.3 \pm 17.2$ & 10 & $178.2 \pm 9.4$ & 192 & $254.4-432.5 \times 76.3-178.1$ \\
\hline \multicolumn{9}{|l|}{ Fish $B$} \\
\hline 120 & 5 & $43.0 \pm 2.3$ & 5 & $409.6 \pm 27.9$ & - & - & - & - \\
\hline 150 & 5 & $56.8 \pm 1.5$ & 6 & $543.8 \pm 21.9$ & - & - & - & - \\
\hline 180 & 6 & $69.6 \pm 3.0$ & 6 & $631.5 \pm 37.8$ & - & 一 & - & - \\
\hline \multicolumn{9}{|l|}{ Fish C } \\
\hline $215^{* *}$ & 5 & $62.7 \pm 2.7$ & 5 & $645.7 \pm 58.4$ & - & - & 2 & $547.0-572.4 \times 178.1-197.2$ \\
\hline 245 & 5 & $91.6 \pm 13.0$ & 5 & $863.5 \pm 71.6$ & - & - & - & - \\
\hline 261 & 2 & $84.8 \pm 3.3$ & 2 & $854.9 \pm 8.6$ & - & - & - & - \\
\hline 299 & 5 & $118.0 \pm 8.0$ & 51 & $1022.1 \pm 34.5$ & - & - & - & - \\
\hline 328 & 5 & $139.6 \pm 12.3$ & 51 & $1139.7 \pm 83.2$ & - & - & - & - \\
\hline 355 & 4 & $172.3 \pm 7.6$ & 41 & $1213.9 \pm 34.5$ & - & - & - & 一 \\
\hline
\end{tabular}

$* 1$ Radius from nucleus to posterior edge of otolith.

*2 Longest radius.

*3 Length (range) $\times$ width (range).

* The time of release into the river.

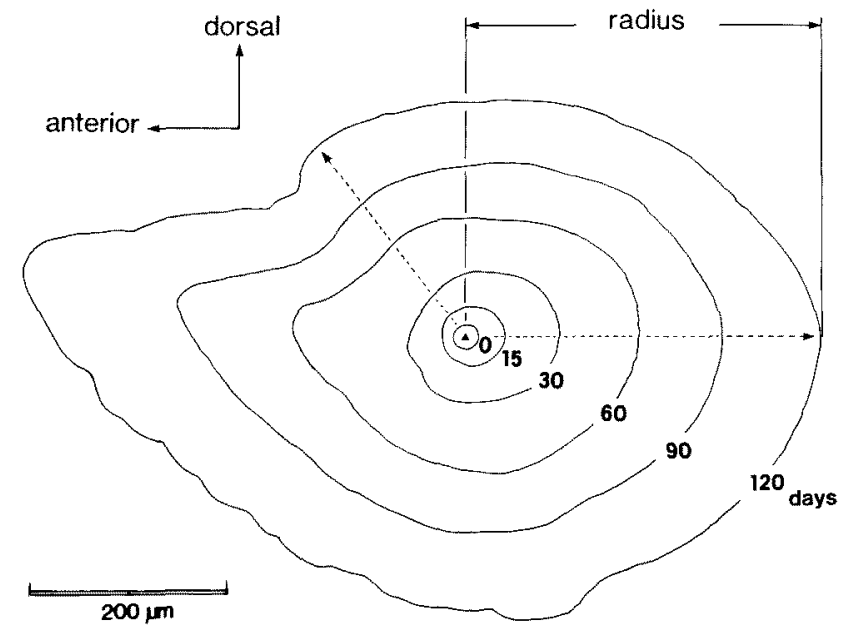

Fig. 2. Growth of sagitta of the ayu. Radius measured is shown and typical counting routes are indicated in broken lines.

is smaller than that of sagitta $(3.0 \mu \mathrm{m})$, and therefore the counting was more difficult. For these reasons, lapillus is not used for the following age determination.
Validation of Increment

Distinct yellow fluorescent band is retained in sagittae of larvae recaptured 6 days after release (Fig. 5). Number of increments outside the 


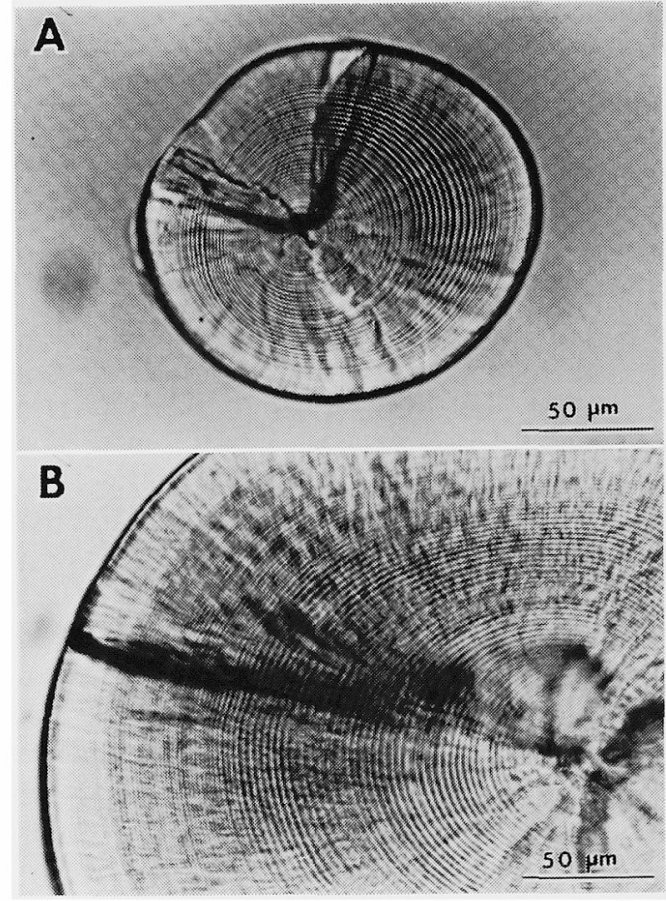

Fig. 3. A: Sagitta of a field collected sample of 18 $\mathrm{mm}$ in SL and 42 days old (estimated). B: Sagitta of a reared fish of $35.5 \mathrm{~mm}$ and 90 days old.

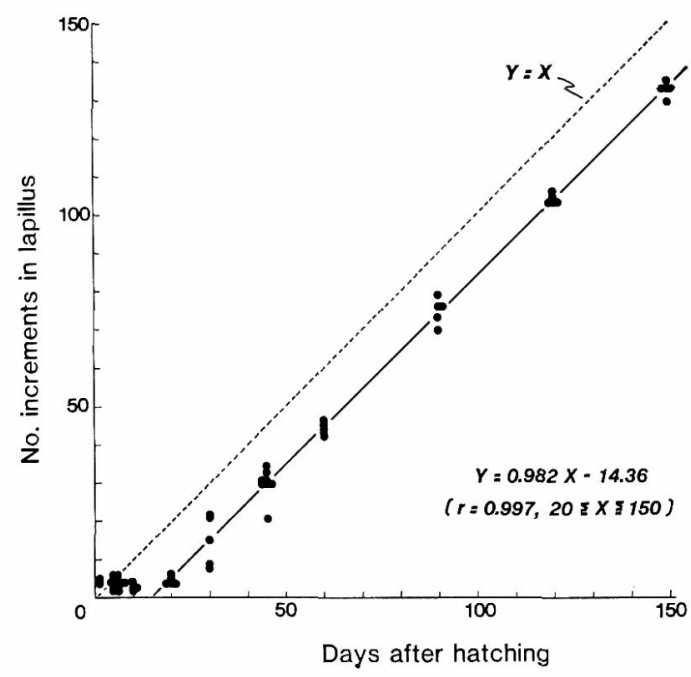

Fig. 4. Increment formation in lapillus. Regression line was obtained from the data of fish older than 20 days (solid line). For comparison, the line of $Y=X$ is shown (dotted line).

fluorescent mark $(Y)$ is linearly correlated with days $(X)$ after marking (Fig. 6). The least square regression is expressed as:

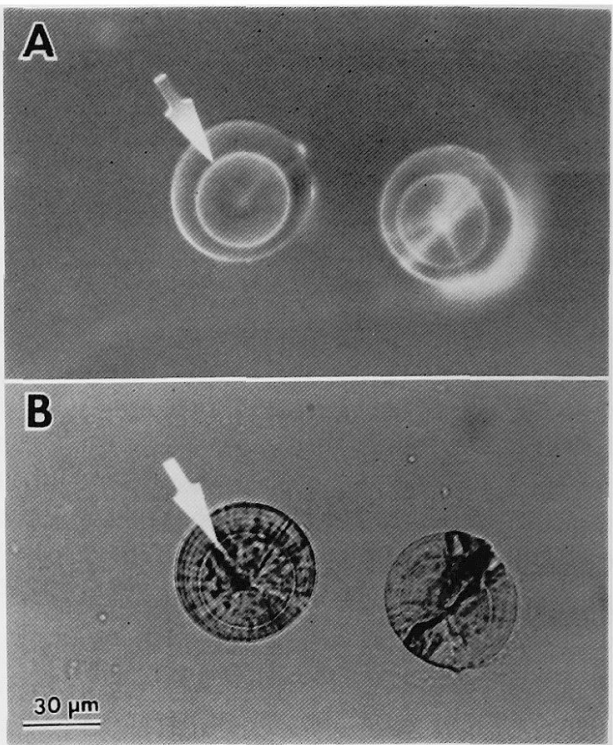

Fig. 5. A: Fluorescent microscopic photograph of sagittae of larva recaptured on the 6th day after the release. Arrow indicates a fluorescent mark of tetracycline. B: Photograph of the same preparation under white light. Increments outside the arrow correspond the period between the release and recapture.

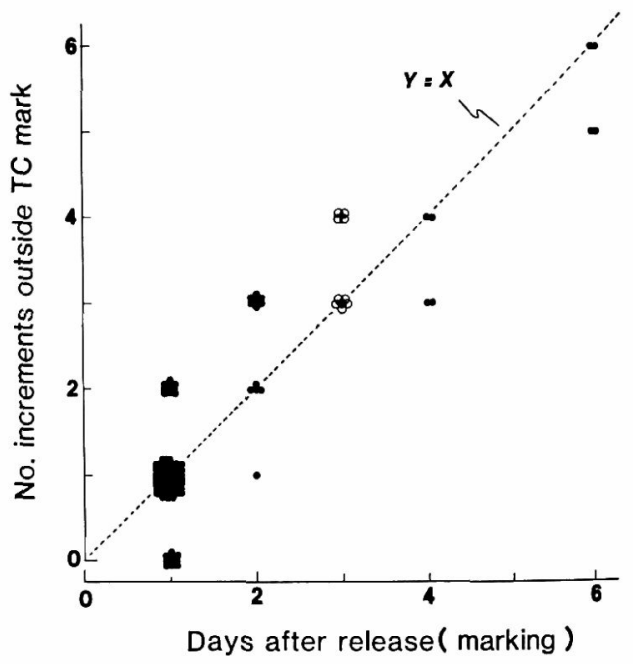

Fig. 6. Relationship between the days after release (marking treatment) and number of increments outside tetracycline mark in sagittae of larvae recaptured in the sea. Solid circle indicates fish marked at larval stage and released at the mouth of the River Nagano, and open circle is that treated at egg stage and released at the lower reaches of the river. As a reference, $Y=X$ is shown. 

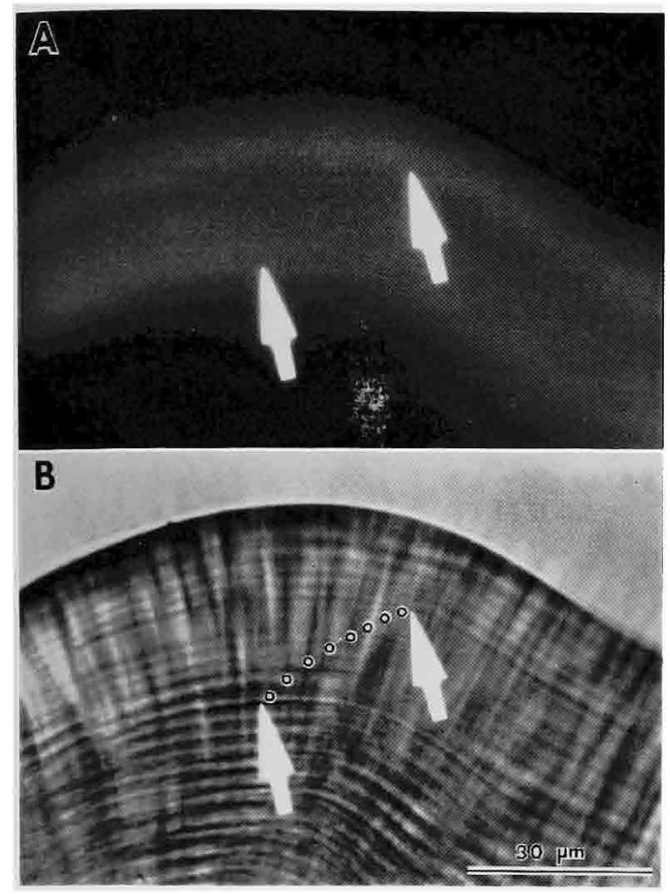

Fig. 7. A: Fluorescent microscopic photograph of sagitta of the juvenile with two injections ( 8 days interval) of tetracycline. Arrow was located at the most brilliant part of each fluorescent band. B: Photograph of the same preparation under white light. Increments between two arrows correspond to the interval of two injections.

$$
Y=0.996 X+0.117(n=186, r=0.8910,1 \leqq X \leqq 6)
$$

The slope is not significantly different from 1 $(p>0.5)$, indicating daily deposition of the increment in a natural environment (sea and river).

Double fluorescent bands are observed in sagittae of all juveniles that were treated with two tetracycline injections (Fig. 7). Number of increments between the two fluorescent bands is 8 in all sagittae of test group, which coincides with the interval between two injections ( 8 days). Furthermore, 7-8 increments (mean, 7.5) are counted between the outer tetracycline band and the edge of otolith, which also roughly coincides with the interval ( 8 days) between the second injection and the day of sacrifice. The minor disaggreement of the latter figures will be due to the counting error of the increments near the edge of the otolith. These clearly demonstrates daily deposition of increments in juveniles. Both the test (tetracycline) and the control $(0.75 \% \mathrm{NaCl}$ solution) groups form similar checks on otolith corresponding to the time of injection, suggesting

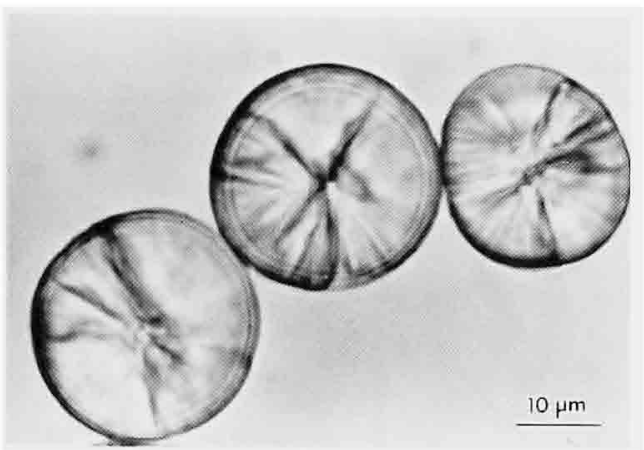

Fig. 8. Otoliths of a newly hatched larva (Fish E). Right small one is lapillus and the other two, sagittae. Embryonic increments are observed in sagittae (ca. 4) and lapillus (ca. 2).

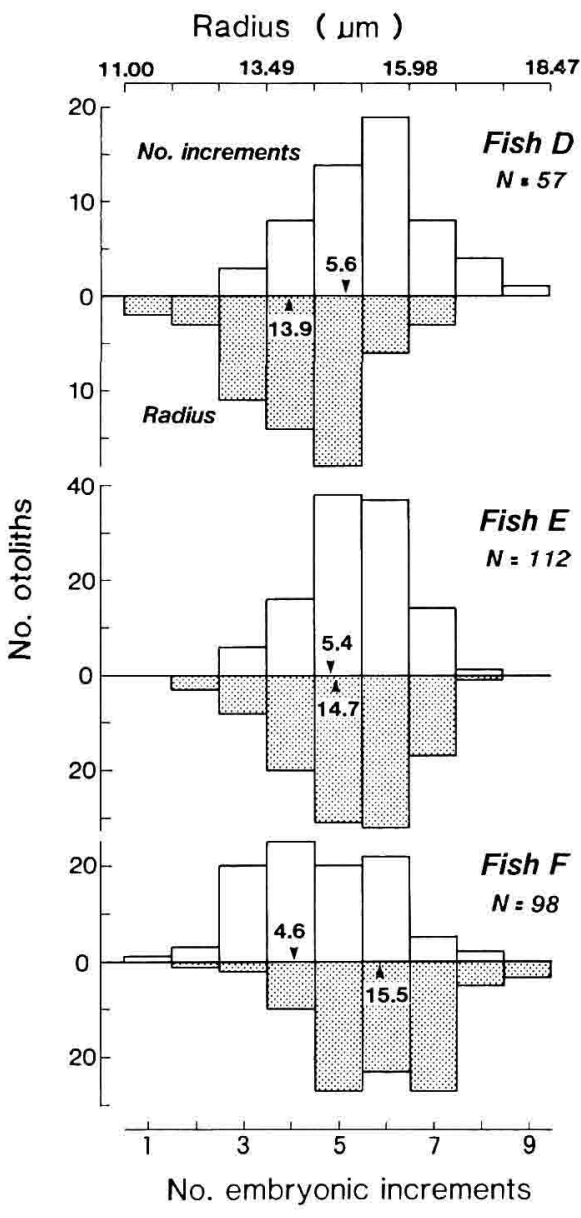

Fig. 9. Frequency distributions of increment number (open) and radius of sagitta (dotted) at hatching in three different groups (Fish D, E, F). Numeral with arrow is a mean. 


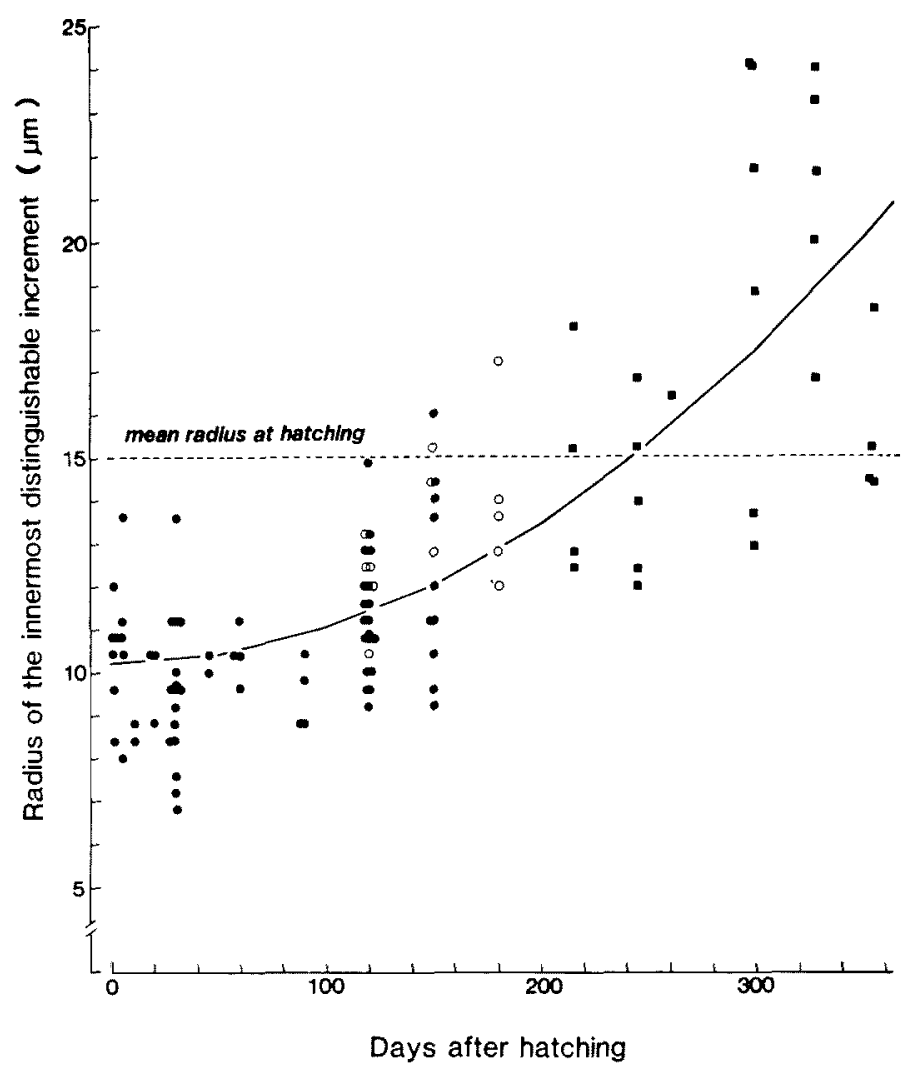

Fig. 10. Change in radius of the innermost distinguishable increments (RIDI) with age. Solid circle represents Fish A (1-150 days), open circle is Fish B (120-180 days) and square is Fish C (215-355 days).

that the check formation is due to the handling during treatment rather than the tetracycline injection. Survival rates of the test and the control groups are ca. 50 and $80 \%$, respectively. Lower rate in the test group might be due to lower $\mathrm{pH}$ value $(2-3)$ of tetracycline solution.

\section{Age Determination}

At hatching, the ayu has already formed several embryonic increments in sagitta, measuring about $0.8 \mu \mathrm{m}$ in mean width (Fig. 8). The mean radius of sagitta at hatching is $14.8 \mu \mathrm{m}$ (mean of all sagittae of Fish D-F). In detail, however, the mean radii at hatching differ among the three groups, Fish D, E and $F(p<0.025$, Fig. 9). The mean number of embryonic increments in Fish $F$ is different from those in the other two ( $p<$ 0.025). Fish $D$ tends to have smaller sagittae with more embryonic increments than the other two groups. On the contrary, Fish $F$ have larger sagittae with fewer increments.

RIDI (Radius of the Innermost Distinguishable
Increment) increases with the days after hatching to exceed the mean radius at hatching $(15 \mu \mathrm{m})$ at the age of ca. 245 days, and the proportion of those individuals increases with age (Fig, 10). RIDI exceeds $15 \mu \mathrm{m}$ (mean neonatal radius) in $75 \%$ of fish older than 250 days. These indicates that the earlier postnatal increments near the center of otolith disappear at a certain age presumably due to the increase in thickeness and the decrease in transparency of otolith. This underestimates the age. The magnitude will be only about 11 days even on the oldest individual examined here, where RIDI is $24 \mu \mathrm{m}$ and the mean width of the early postnatal increments is $0.8 \mu \mathrm{m}$.

The number of sagittal increments outside the $15 \mu \mathrm{m}$ radius $(Y)$ correlates linearly with the days after hatching $(X)$ (Fig. 11, Table 3), and the relationships for Fish A, B and C are expressed by the following least square regressions:

Fish A $Y=1.007 X-1.029$

$$
(n=92, r=0.9997, \quad 1 \leqq X \leqq 150)
$$

Fish B $\quad Y=0.950 X+5.229$ 
Table 3. Number of growth increments in sagittae and the counting error

\begin{tabular}{|c|c|c|c|c|c|c|c|c|}
\hline \multirow{2}{*}{$\begin{array}{c}\text { Age } \\
\text { (cay) }\end{array}$} & \multirow{2}{*}{$\begin{array}{l}\text { No. } \\
\text { fish }\end{array}$} & \multirow{2}{*}{$\begin{array}{l}\text { SL (mm) } \\
\text { mean } \pm S D\end{array}$} & \multirow{2}{*}{$\begin{array}{l}\text { No. } \\
\text { otolith }\end{array}$} & \multicolumn{3}{|c|}{ No. increments with radius $>15 \mu \mathrm{m}$} & \multirow{2}{*}{$\begin{array}{l}\text { Error of } \\
\text { the mean } \\
\text { day }(\%)\end{array}$} & \multirow{2}{*}{$\begin{array}{l}\text { Maximum } \\
\text { error } \\
\text { day }(\%)\end{array}$} \\
\hline & & & & mean $\pm S D$ & $V^{* 1}$ & range (width) & & \\
\hline \multicolumn{9}{|l|}{ Fish $A$} \\
\hline 1 & 13 & $5.7 \pm 0.2$ & 17 & $1.0 \pm 0.0$ & 0.0 & $1-\quad 1(0)$ & $0.0(0.0)$ & $0(0.0)$ \\
\hline 5 & 13 & $6.8 \pm 0.4$ & 16 & $4.1 \pm 0.6$ & 14.3 & $3-5(2)$ & $-0.9(18.0)$ & $-2(40.0)$ \\
\hline 10 & 6 & $8.1 \pm 0.8$ & 12 & $8.6 \pm 0.5$ & 6.2 & $8-10(2)$ & $-1.4(14.0)$ & $-2(20.0)$ \\
\hline 20 & 6 & $11.1 \pm 1.7$ & 10 & $18.5 \pm 0.8$ & 4.1 & $17-19(2)$ & $-1.5(7.5)$ & $-3(15.0)$ \\
\hline 30 & 6 & $16.2 \pm 1.5$ & 11 & $28.8 \pm 0.5$ & 1.6 & $28-30(2)$ & $-1.2(4.0)$ & $-2(6.7)$ \\
\hline 45 & 7 & $24.2 \pm 1.5$ & 12 & $43.5 \pm 0.4$ & 0.9 & $43-44(1)$ & $-1.5(3.3)$ & $-2(4.4)$ \\
\hline 60 & 6 & $29.5 \pm 1.2$ & 6 & $59.2 \pm 1.8$ & 3.0 & $58-61(3)$ & $-0.8(1.3)$ & $-2(3.3)$ \\
\hline 90 & 6 & $35.5 \pm 1.5$ & 6 & $89.0 \pm 1.0$ & 1.1 & $87-90(3)$ & $-1.0(1.1)$ & $-3(3.3)$ \\
\hline 120 & 20 & $43.5 \pm 3.2$ & 31 & $119.7 \pm 1.4$ & 1.2 & $116-124(8)$ & $-0.3(0.3)$ & $-4(3.3)$ \\
\hline 150 & 9 & $50.3 \pm 4.1$ & 10 & $151.0 \pm 2.8$ & 1.8 & $148-157(9)$ & $+1.0(0.6)$ & $+7(4.7)$ \\
\hline \multicolumn{9}{|l|}{ Fish $B$} \\
\hline 120 & 5 & $43.0 \pm 2.3$ & 5 & $121.4 \pm 2.7$ & 2.2 & $117-125(8)$ & $+1.4(1.2)$ & $+5(4.2)$ \\
\hline 150 & 5 & $56.8 \pm 1.5$ & 6 & $143.2 \pm 4.2$ & 2.9 & $137-148(11)$ & $-6.8(4.5)$ & $-13(8.7)$ \\
\hline 180 & 6 & $69.6 \pm 3.0$ & 6 & $178.0 \pm 3.0$ & 1.7 & $175-184(9)$ & $-2.0(1.1)$ & $-5(2.8)$ \\
\hline \multicolumn{9}{|c|}{ 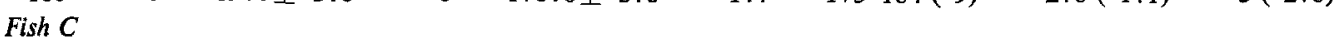 } \\
\hline $215^{* 2}$ & 5 & $62.7 \pm 2.7$ & 5 & $210.2 \pm 1.7$ & 8.2 & $208-213(5)$ & $-4.8(2.2)$ & $-7(3.3)$ \\
\hline 245 & 5 & $91.6 \pm 13.0$ & 5 & $244.4 \pm 5.0$ & 2.0 & $240-253(13)$ & $-0.6(0.2)$ & $+8(3.3)$ \\
\hline 261 & 2 & $84.8 \pm 3.3$ & 2 & $256.0 \pm 8.0$ & 3.1 & $248-264(16)$ & $-5.0(1.9)$ & $-13(5.0)$ \\
\hline 299 & 5 & $118.0 \pm 8.0$ & 5 & $295.6 \pm 13.9$ & 4.7 & $279-318(39)$ & $-3.4(1.1)$ & $-20(7.2)$ \\
\hline 328 & 5 & $139.6 \pm 12.3$ & 5 & $312.8 \pm 13.6$ & 4.3 & $293-331(38)$ & $-15.2(4.6)$ & $-35(10.7)$ \\
\hline 355 & 4 & $172.3 \pm 7.6$ & 4 & $332.0 \pm 6.5$ & 2.0 & $326-343(17)$ & $-23.0(6.5)$ & $-29(8.2)$ \\
\hline
\end{tabular}

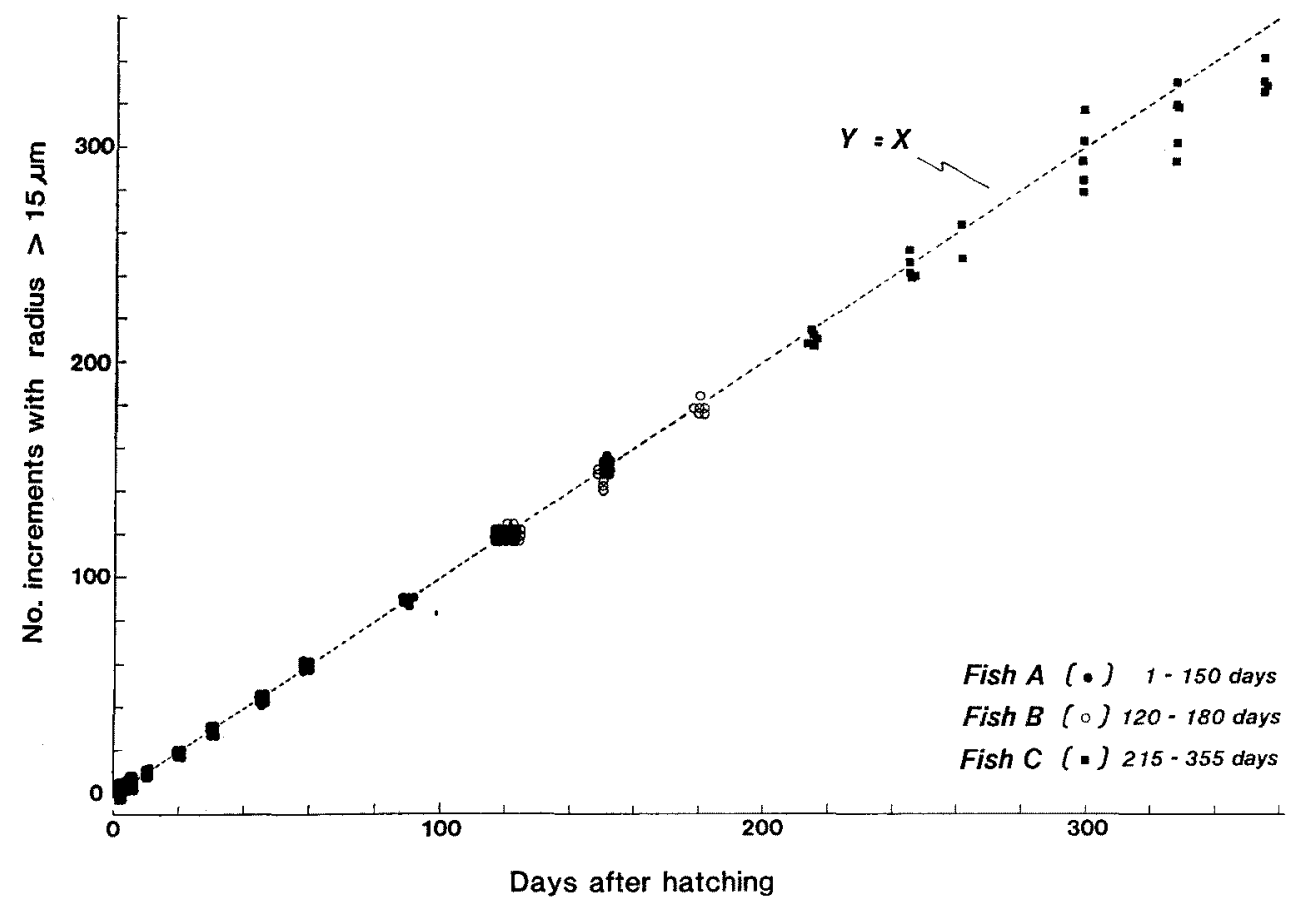

Fig. 11. Relationship between days after hatching and the number of increments with the radius more than $15 \mu \mathrm{m}$ in three groups, Fish A, B and C. The diagonal line is for the expected relationship $(Y=X)$. 


$$
\begin{array}{ll} 
& (n=16, r=0.9824,120 \leqq X \leqq 180) \\
\text { Fish C } & Y=0.871 X+28.08 \\
& (n=26, r=0.9715,215 \leqq X \leqq 355)
\end{array}
$$

Fish of different history (Fish A and B) have the same number of increments at the age of 120 and 150 days (Fig. 11), suggesting a uniform deposition rate for different fish groups.

The slopes of three regressions differ significantly one another $(p<0.01)$, and the older group has smaller value. The slope of regression for Fish B does not differ significantly from $1(p>0.2)$, while those for Fish A and C did $(p<0.01)$. The slope for Fish A (1.007) differs from 1 because of high value of coefficient of correlation and large sample size. We conclude, however, that the regression of Fish $\mathbf{A}$ as well as Fish B provides support of the daily increment deposition in sagitta in addition to the validation of increments

\begin{tabular}{|c|c|c|c|}
\hline \multirow{2}{*}{$\begin{array}{c}\text { Age } \\
\text { (day) }\end{array}$} & \multirow{2}{*}{ Count } & \multicolumn{2}{|c|}{ Difference } \\
\hline & & No. & $\%^{*}$ \\
\hline \multirow[t]{5}{*}{1} & 5,6 & 1 & 18.2 \\
\hline & 6,6 & 0 & 0 \\
\hline & 6,7 & 1 & 14.9 \\
\hline & 7,7 & 0 & 0 \\
\hline & mean & 0.5 & 8.3 \\
\hline \multirow[t]{7}{*}{10} & 10,11 & 1 & 9.5 \\
\hline & 12,13 & 1 & 8.0 \\
\hline & 12,14 & 2 & 15.4 \\
\hline & 12,14 & 2 & 15.4 \\
\hline & 13,14 & 1 & 7.4 \\
\hline & 13,14 & 1 & 7.4 \\
\hline & mean & 1.3 & 10.5 \\
\hline \multirow[t]{6}{*}{45} & 43,46 & 3 & 6.7 \\
\hline & 46,47 & 1 & 2.2 \\
\hline & 47,49 & 2 & 4.2 \\
\hline & 47,50 & 3 & 6.2 \\
\hline & 50,52 & 2 & 3.9 \\
\hline & mean & 2.2 & 4.6 \\
\hline \multirow[t]{12}{*}{120} & 118,119 & 1 & 0.8 \\
\hline & 120,123 & 3 & 2.5 \\
\hline & 121,124 & 3 & 2.4 \\
\hline & 121,124 & 3 & 2.4 \\
\hline & 122,123 & 1 & 0.8 \\
\hline & 122,124 & 2 & 1.6 \\
\hline & 122,124 & 2 & 1.6 \\
\hline & 123,123 & 0 & 0 \\
\hline & 123,124 & 1 & 0.8 \\
\hline & 124,124 & 0 & 0 \\
\hline & 124,127 & 3 & 2.4 \\
\hline & mean & 1.7 & 1.4 \\
\hline
\end{tabular}

Table 4. Difference of total increment counts between left and right sagittae

* Percentage of difference between two counts to their median. by tetracycline marking.

Coefficient of variation of the increment count tends to increase with the increasing age of fish from 50-150 days, $120-180$ days and to $215-355$ days (Table 3). Error of the count (expressed by the difference between the true age and the mean of increment counts) does not exceed 2 days till 150 days (Table 3 ) and even in the oldest sample (355 days), it was 23 days $(6.5 \%)$. Maximum error was 35 days $(10.7 \%)$ in fish of 328 days old. Therefore, we conclude that the error of this age determination technique gives almost unbiased estimate within the error of 5 days $(2 \%)$, till 300 days after hatching, although it will underestimate the true age of the older fish. In addition, bilateral differences of sagittal counts of 120 days old fish are within 3 layers and within $2.5 \%$ of the true age (Table 4). Absolute bilateral diversity increase with the age of fish, but the relative diversity decrease. Correlation between the number of sagittal increments and standard length of the fish is not significant $(p>0.3)$ in 120 -old-fish. This indicates that the deposition rate is independent from the growth rate of fish.

\section{Discussion}

We confirmed that the ayu deposited clear daily growth increments in otolith for the entire life time. The daily increments in the ayu otolith seem to be the clearest and the most regular in the periodicity of deposition among species which have ever been studied. It is also noteworthy that we have determined the deposition rate in larvae and juvenile-adult using mark-recapture methods in natural environments for the first time. No fish can be aged in daily precision throughout all his life history. The ayu, however, can be practically aged for almost all over the life span, since the error of the mean counts does not exceed 5 days $(2 \%)$ till 300 days old. This has a potential to be a useful tool in the ecological study and population dynamics of this species.

The following factors, however, may cause a small error and bias in age determination of the ayu; (1) age-associated disappearence of early layers, (2) formation of checks (conspicuous opaque bands), (3) occurrence of subdialy increments, (4) timing of the first increment formation, and (5) resolving power of a microscope.

\section{Age-associated Disappearence of Early Layers}

Underestimation of age occurs in older individuals, since the mean radius of the innermost 
distinguishable increment (RIDI) starts to exceed the mean sagitta radius at hatching $(15 \mu \mathrm{m})$ at the age of $\mathbf{2 4 5}$ days and the proportion of those individuals increases with age (Fig. 10). This occurred on $75 \%$ fish over 250 days, and the individual ages thus underestimated would be 1-11 days (Fig. 10). However, the age-associated expansion of invisible area causes no disadvantage in ageing fish younger than 200 days. Preservation of mounted otolith up to 2-3 years does not cause the decrease of transparency or any other adverse effects on counting layers.*

\section{Formation of Checks}

Check seems to correspond to the temporary cessation of increment deposition by physiological stress. Therefore, check formation causes underestimation of the age. Check frequency increased with increasing age, particularly in sexually mature fish. ${ }^{3)}$ Most of the ayu older than 200 days had 1-3 checks in sagitta. Although direct cause of check formation is unclear, an artificially given abrupt change in salinity (from 35\% to $0 \%$ in a few hours) produced an extraordinary heavy check corresponding to the cessation of increment formation for 3-7 days. ${ }^{* 7}$ Therefore, the underestimation of age due to the check formation expected to be, roughly 3-21 days for fish older than 200 days.

The formation of check was not necessarily synchronous even among fish that experienced the same environmental changes in a culture pond.* Migration or habitat transition in life history seemed to influence the otolith microstructure in French grunts, ${ }^{8)}$ coaral-reef wrasses ${ }^{9)}$ and juvenile chinook salmon. ${ }^{10)}$ The ayu shows amphidromous migration, from freshwater to the sea at larval stage and vice versa at juvenile stage. However, check or abrupt change in increment width did not strictly correspond to the timing of migration from river to the sea and vice versa. ${ }^{* 7}$

\section{Occurrence of Subdaily Increments}

The incidence of subdaily increments is one of the main sources of error in age determination of various fish species. It's presence may cause overestimation of age when they are dealt as daily layer or underestimation when daily layers are confused with subdaily ones, although the magnitude can not be estimated. The ayu sometimes produces subdaily increments (2-3 increments per day) in the posterior part of sagitta (Fig. 12). Subdaily increments do not cause problem in the ayu younger than 150 days since they can be easily identified by the abrupt change in width of the sequential increments (Fig. 12), while they cause some difficulty in older fish. So far as the photographs of otoliths are compared, however, the identification of subdaily increments seems to be much easier in the ayu than in the pumpkinseed, ${ }^{11}$ ) chinook salmon, ${ }^{12)}$ sockeye salmon, ${ }^{13)}$ red sea bream $^{14)}$ and starry flounder. ${ }^{15)}$

Excess feeding accompanied by high rearing temperature resulted in higher growth rate of juvenile ayu and caused wide daily increments each of which included 2-3 subdaily ones. ${ }^{* 7}$ In

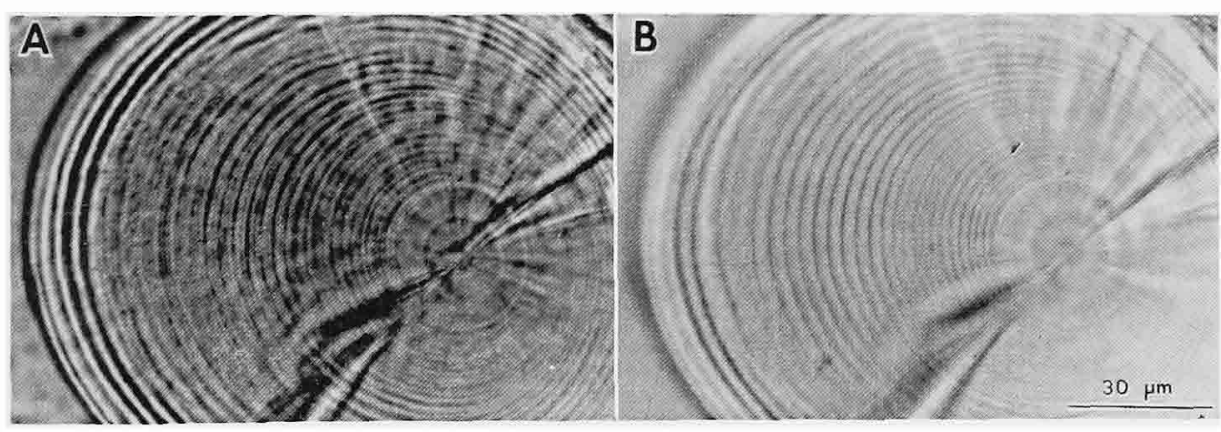

Fig. 12. A: Sagitta of 30 days old fish (Fish A) showing 2-3 subdaily increments in each of increments corresponding to ca. 10-22 days after hatching. The focus was exactly adjusted. B: The same preparation under intentional off-focus condition. Subdaily increments vanish, whereas daily ones are remained. This technique is convenient in identification of subdaily increments through light microscopy.

* Tsukamoto and Kajihara, unpublished.

*7 Tșukamoto et al., unpublished. 
general, feeding frequency and temperature level, within range promoting regular growth, seem to be of secondary importance to the regularity of increment formation but have an influence on the width of increment. ${ }^{2,11-13,18)}$ In contrast, Geffen $^{17)}$ suggested that increment number was a simple function of growth rate in larval turbot and herring. The effects of temperature, feeding frequency and resulting growth rate on the deposition rate of increments are still conflicting and controversial in many species. This may be derived from the interspecific differences, or from the differences in the apparatus and the level of counting technique.

In addition, incomplete layer at the edge of otolith may cause one day overestimation of the age. Birefringence at the edge also have potential to produce a small error ( \pm 1 day).

\section{Timing of the First Increment Formation}

The other source of error is the timing of first increment formation, or the identification of increment at hatching. Hatch checks are often used as bench marks from which increment counts are made. ${ }^{12,13)}$ However, the ayu does not produce a check peculiar to the timing of hatch. We conventionally determined the increment at hatching based on the mean radius of otolith at hatching. If we had identified it simply using the mean number of embryonic increments, underestimation of age could have occurred because of ageassociated disappearance of the early layers.

Different species start increment deposition at different ages: e.g. 2-3 days before hatching in California grunion ${ }^{18)}$ and mummichog, ${ }^{27}$ at swim up in three species of Lepomis, $^{11}{ }^{11}$ at yolk-sac absorption or first feeding in northern anchovy, ${ }^{187}$ English sole ${ }^{19)}$ and Japanese anchovy. ${ }^{20)}$ The ayu has more number of embryonic increments at hatching than these species. If the embryonic increments of the ayu are also supposed as daily, the ayu embryo in this study (Fish D-F) are supposed to have deposited the first increment $c a .5$ days before hatching (7 days after fertilization). Iwai ${ }^{211}$ reported that the ayu embryo incubated at $18^{\circ} \mathrm{C}$ developed the auditory vesicle at 3.3 days after fertilization, and otoliths (sagitta and lapillus) at 4.0 days. It completed external structure of eye at 5.6 days, and fully established the sensory retinae at 9.6 days. ${ }^{21}$ The timing of first increment formation seems to coincide with the functionization of retinae, although strict com- parison between Iwai's result and ours cannot be done because of different experimental temperatures.

Embryos incubated at higher temperature had smaller otolith with more embryonic increments at hatching (Fig. 9). Ito et al. ${ }^{22)}$ demonstrated that the ayu embryo incubated at higher temperature hatched earlier at smaller body size than those at lower temperature in the range of temperature higher than $17^{\circ} \mathrm{C}$. Therefore, the embryo incubated at higher temperature would have smaller otolith since otolith size and body length have a strong positive relationship.*8 On the other hand, high temperature seems to accelerate the development of retinae and the first increment will be formed early. Accordingly, the embryo incubated at higher temperature may have more embryonic increments at hatching than those at lower temperature, notwithstanding the contraction of incubation time.

Difference in the parental stocks and/or the environmental conditions may change the incubation period, the number of embryonic increments and the size of otolith at hatching. The last factor may cause a few days error in ageing of the present study and this will be significant in ageing larvae. Therefore, if the larvae of a certain population are aged, the mean otolith size at hatching particular to the population has to be determined using in situ incubation method; e.g. $13.9 \mu \mathrm{m}$ for land-locked stock in the Lake Biwa, and $15.5 \mu \mathrm{m}$ for amphidromous stock in the River Shinano.

\section{Resolving Power of a Microscope}

Campana and Neilson ${ }^{8)}$ stressed that limitation of resolving power of light microscopy might cause underestimation of true age by missing increments narrower than the theoretical resolution limit $(0.2 \mu \mathrm{m})$. The minimum increment width was estimated as about $0.8 \mu \mathrm{m}$ in the ayu otolith. This is much wider than the resolution limit of light microscopy. Light microscope has an advantage in the identification of daily and subdaily increments (Fig. 12). Furthermore, scanning electron microscopic observation requires time consuming procedure; e.g. mounting, grinding, polishing, etching and photo processing. Notwithstanding some limitations of light microscopy, nothing in other methods can be substituted for quickness and flexibility in light microscopy, which is an indispensable factor for the study dealing with a

* Tsukamoto et al., unpublished. 
large amount of sample.

\section{Acknowledgements}

We express our gratitude to Fumiko Hosokawa for her help in preparation and observation of otoliths. The following persons generously provided materials for this study: Tohru Ando (Kunisaki Branch, Oita Pref. Sea Farming Center), Yoshiharu Hiramoto (Hiroshima Pref. Sea Farming Association), Yasuyoshi Murakami (Freshwater Fish Branch, Hiroshima Pref. Fisheries Experimental Station), Noriyuki Hyodo (Niigata Pref. Freshwater Fisheries Experimental Station), and the staff of Shiga Pref. Fisheries Experimental Station, Gunma Pref. Fisheries Experimental Station and Gifu Pref. Ayu Hatchery. Minoru Endo (Oita Pref. Freshwater Fisheries Experimental Station) and the staff of Ugui Marine Biological Station helped us in the mark-recapture experiments in the River Tsubusa, and the Ugui Cove, respectively. Sachiko Tsuji (Southwest Fisheries Center, NOAA, USA) provided an introduction to otolith techniques. Thanks to Rikizo Ishida (Tokai Regional Fisheries Research Laboratory) for his help with statistical analysis of the data. We gratefully acknowledge helpful criticisms by Toshio Kasuya (Far Seas Fisheries Research Laboratory) and Masaru Tanaka (Kyoto University).

\section{References}

1) G. Pannella: Science (Wash., D. C.), 173, 1124 1127 (1971).

2) R. L. Radtke and J. M. Dean: Fish. Bull., U.S., 80, 201-215 (1982).

3) S. E. Campana and J. D. Neilson: Can. J. Fish. Aquat. Sci., 42, 1014-1032 (1985).

4) M. Yokote: Bibliography of the study of ayu for the years 1950-1978, Freshwater Fisheries
Research Laboratory, Tokyo, Japan, 1978, pp. 1-112.

5) M. Yokote: Bibliography of the study of ayu for the years 1978-1984, Tokai Regional Fisheries Research Laboratory, Tokyo, Japan, 1985, pp. 1-82.

6) K. Tsukamoto: Nippon Suisan Gakkaishi, 51, 903-911 (1985).

7) Y. Mugiya, N. Watabe, J. Yamada, J. M. Dean, D. G. Dunkelberger, and M. Shimizu: Comp. Biochem. Physiol., 68A, 659-662 (1981).

8) E. B. Brothers and W. N. McFarland: Rapp. P.-v. Reun. Cons. Int. Explor. Mer., 178, 369-374 (1981).

9) B. C. Victor: Mar. Biol., 71, 203-208 (1982).

10) J. D. Neilson, G. H. Geen, and D. Bottom: Can. J. Fish. Aquat. Sci., 42, 899-908 (1985).

11) B. D. Taubelt and D. W. Coble: J. Fish. Res. Board Can., 34, 332-340 (1977).

12) J. D. Neilson and G.H. Geen: Can. J. Fish. Aquat. Sci., 39, 1340-1347 (1982).

13) S. L. Marshall and S. S. Parker: Can. J. Fish. Aquat. Sci., 39, 542-547 (1982).

14) S. Tsuji and T. Aoyama: Nippon Suisan Gakkaishi, 48, 1559-1562 (1982).

15) S. E. Campana: Can. J. Zool., 61, 1591-1597 (1983).

16) S. E. Campana: Fish. Bull. U.S., 82, 165-177 (1984).

17) A. J. Geffen: Mar. Biol., 71, 317-326 (1982).

18) E. B. Brothers, C. P. Mathews, and R. Lasker: Fish. Bull., U. S., 74, 1-8 (1976).

19) J. L. Laroche, S. L. Richardson, and A. A. Rosenberg: Fish. Bull., U. S., 80, 93-104 (1982).

20) S. Tsuji and T. Aoyama : Nippon Suisan Gakkaishi, 50, 1105-1108 (1984).

21) T. Iwai: Bull. Misaki Mar. Biol. Inst,, Kyoto Univ., 2, 1-101 (1962).

22) T. Ito, T. Tomita, and T. Iwai: Artificial Propagation of ayu fish. Institute of Limnology and Freshwater Fish Culture, Faculty of Fisheries, Prefectural University of Mie, Tsu, Japan, 1971, pp. 57-98. 